\title{
ГОТОВНОСТЬ ОБУЧАЮЩИХСЯ К ОПЕРЕЖАЮЩЕЙ ПРОФЕССИОНАЛЬНОЙ ПОДГОТОВКЕ КАК МЕТАПРЕДМЕТНАЯ КОМПЕТЕНЦИЯ ШКОЛЬНОГО ОБРАЗОВАНИЯ
}

\section{STUDENTS' READINESS FOR ADVANCED VOCATIONAL TRAINING AS A MESO-SUBJECT COMPETENCE OF SCHOOL EDUCATION.}

\section{G. Kashfrazieva}

Summary: The issues of early professional self-determination of schoolchildren are raised at the highest level and the importance of early professional self-determination is reflected in the relevant state documents regulating the educational process. Professional development is not a benchmark for education from the standpoint of the content of the Federal State Educational Standard, which makes it necessary to find a place for this issue in the school education system. The task can be solved by correlating it with the results of education according to the Federal State Educational Standard.

Keywords: professional self-determination of schoolchildren, subject area "Technology", advanced vocational training, vocational guidance of students, education.

\author{
Кашфразыева Гульнара Камилевна \\ Аспирант, Елабужский институт Казанского \\ (Приволжского) Федерального университета, \\ Россия, г. Елабуга \\ gulnara2511@bk.ru
}

Аннотация: Вопросы раннего профессионального самоопределения школьников поднимаются на самом высоком уровне и значение раннего профессионального самоопределения отражено в соответствующих государственных документах, регламентирующих образовательный процесс. Профессиональное развитие не является ориентиром для образования с позиции содержания требования ФГОС, что вызывает необходимость найти место данной проблематики в системе школьного образования. Задача может быть решена посредством её соотнесения с результатами образования по ФГОС.

Ключевые слова: профессиональное самоопределение школьников, предметная область «Технология», опережающая профессиональная подготовка, профессиональная ориентация обучающихся, образование.
$\mathrm{O}$ сновные тренды развития образования в современном мире связаны с необходимостью обеспечения максимально ранней профессиональной ориентацией обучающихся, что, в частности, выдвигает требования к формированию у них готовности к опережающей профессиональной подготовки как некоторого интегративного качества, определяющего общий уровень эффективности их профориентационной деятельности. Значение раннего профессионального самоопределения отражено в соответствующих государственных документах, регламентирующих образовательный процесс. В частности, президент Российской Федерации В.В. Путин говорил о раннем профессиональном самоопределении и эти вопросы поднимаются на самом высоком уровне [3].

Вместе с тем перспективное профессиональное развитие не является непосредственно ориентиром для образования с позиции содержания требований федеральных государственных образовательных стандартов, что вызывает необходимость найти место данной проблематики в системе школьного образования, учитывая, что предметная область «Технология» преподается в школе в среднем звене. Задача может быть решена только посредством её соотнесения с результатами образования по ФГОС, поскольку именно они являются ориентирами, обязательными к достижению в профессионально-педагогической деятельности [4].

Прежде всего речь идет о метапредметных результатах. Именно они играют важнейшую методологическую роль в образовании, носят достаточно широкий характер, позволяющий, в контексте метапредметности, определить значение готовности опережающей профессиональной подготовки, ее конкретное содержание.

Детализация этих результатов приведена в Таблице 1. В их числе важное значение имеют: профессиональное самоопределение, перспективное профессиональное развитие как метакомпетенция человека в современном мире, что связано с развитием возможностей профессионального обучения, освоения навыков в динамично развивающихся условиях профессиональной сферы.

В контексте проблем опережающей профессиональной подготовки предполагается, что обучающиеся получат компетенции не только самостоятельно определять цели своего обучения, ставить и формулировать для себя новые задачи в учёбе и познавательной деятельности, развивать мотивы и интересы своей познаватель- 
Таблица 1.

Детализация метапредметных результатов образования с учетом задач

опережающей профессиональной подготовки

\section{Результат образования по ФГОС 000}

1) умение самостоятельно определять цели своего обучения, ставить и формулировать для себя новые задачи в учёбе и познавательной деятельности, развивать мотивы и интересы своей познавательной деятельности;

2) умение самостоятельно планировать пути достижения целей, в том числе альтернативные, осознанно выбирать наиболее эффективные способы решения учебных и познавательных задач;

3) умение соотносить свои действия с планируемыми результатами, осуществлять контроль своей деятельности в процессе достижения результата, определять способы действий в рамках предложенных условий и требований, корректировать свои действия в соответствии с изменяющейся ситуацией;

4) умение оценивать правильность выполнения учебной задачи, собственные возможности её решения;

5) владение основами самоконтроля, самооценки, принятия решений и осуществления осознанного выбора в учебной и познавательной деятельности;

6) умение определять понятия, создавать обобщения, устанавливать аналогии, классифицировать, самостоятельно выбирать основания и критерии для классификации, устанавливать причинно-следственные связи, строить логическое рассуждение, умозаключение (индуктивное, дедуктивное и по аналогии) и делать выводы;

9) умение организовывать учебное сотрудничество и совместную деятельность с учителем и сверстниками; работать индивидуально и в группе: находить общее решение и разрешать конфликты на основе согласования позиций и учёта интересов; формулировать, аргументировать и отстаивать своё мнение;

10) умение осознанно использовать речевые средства в соответствии с задачей коммуникации для выражения своих чувств, мыслей и потребностей; планирования и регуляции своей деятельности; владение устной и письменной речью, монологической контекстной речью;

11) формирование и развитие компетентности в области использования информационно-коммуникационных технологий (далее ИКТ- компетенции);

12) формирование и развитие экологического мышления, умение применять его в познавательной, коммуникативной, социальной практике и профессиональной ориентации.

ной деятельности, но и смогут адаптировать данную компетентность к дальнейшей профессиональной деятельности и смогут самостоятельно определять цели своей опережающей профессиональной подготовки, ставить и формулировать для себя новые задачи в профессиональной подготовке и профориентационной деятельности, развивать мотивы и интересы своего профессионального развития.
Детализация результата

1) умение самостоятельно определять цели своей опережающей профессиональной подготовки, ставить и формулировать для себя новые задачи в профессиональной подготовке и профориентационной деятельности, развивать мотивы и интересы своего профессионального развития;

2) умение самостоятельно планировать пути достижения целей опережающей профессиональной подготовки, в том числе альтернативные, осознанно выбирать наиболее эффективные способы решения задач опережающей профессиональной подготовки;

3) умение соотносить свои действия с планируемыми результатами опережающей профессиональной подготовки, осуществлять контроль своей профориентационной деятельности, корректировать свою профессиональную подготовку в соответствии с изменяющейся профориентационной ситуацией;

4) умение оценивать правильность выполнения задачи опережающей профессиональной подготовки и возможности её решения;

5) владение основами самоконтроля, самооценки, принятия решений в опережающей профессиональной подготовке и осуществления осознанного выбора в профессиональной деятельности;

6) умение определять понятия, создавать обобщения в сфере профессиональной подготовки, устанавливать аналогии, классифицировать, самостоятельно выбирать основания и критерии для классификации явлений и процессов опережающей профессиональной подготовки, устанавливать причинно-следственные связи, строить логическое рассуждение, умозаключение (индуктивное, дедуктивное и по аналогии) и делать выводы;

9) умение организовывать учебное сотрудничество и совместную деятельность с учителем и сверстниками в области профессиональной подготовки; формулировать, аргументировать и отстаивать своё мнение в отношении проблем опережающей профессиональной подготовки;

10) умение осознанно использовать речевые средства в соответствии с задачей профессиональной коммуникации для выражения своих чувств, мыслей и потребностей в области опережающей профессиональной подготовки; планирования и регуляции своей профориентационной деятельности;

11) формирование и развитие компетентности в области использования информационно-коммуникационных технологий в решении задач опережающей профессиональной подготовки;

12) умение применять экологическое мышление в профессиональной ориентации и в решении задач опережающей профессиональной подготовки.

В контексте профессиональной подготовки обучающихся метапредметная компетенция - умение самостоятельно планировать пути достижения целей, в том числе альтернативные, осознанно выбирать наиболее эффективные способы решения учебных и познавательных задач приобретает вид: умение самостоятельно планировать пути достижения целей опережающей профессиональной подготовки, в том числе альтернативные, 
осознанно выбирать наиболее эффективные способы решения задач опережающей профессиональной подготовки.

Опережающая профессиональная подготовка имеет целенаправленный характер. И при данной деятельности необходимо соотносить свои действия с планируемыми результатами осуществлять контроль своей профориентационной деятельности, корректировать свою профессиональную подготовку в соответствии с изменяющейся профориентационной ситуацией. Данные умения соотносятся с требованиями федерального государственного образовательного стандарта: умение соотносить свои действия с планируемыми результатами, осуществлять контроль своей деятельности в процессе достижения результата, определять способы действий в рамках предложенных условий и требований, корректировать свои действия в соответствии с изменяющейся ситуацией (п.3, таблица 1) и умение оценивать правильность выполнения учебной задачи, собственные возможности её решения (п.4, таблица 1).

Одной из составляющей опережающей профессиональной подготовки является осознанный выбор в профессиональной деятельности, адекватная оценка своих ресурсов и способностей и самоконтроль при осуществление данной деятельности. Данные требования соотносится с метапредметной компетенцией: владение основами самоконтроля, самооценки, принятия решений и осуществления осознанного выбора в учебной и познавательной деятельности (п.5, таблица 1).

Любая деятельность связанная с освоением нового в том числе и профессиональная подготовка невозможна без владения инструментария необходимого для работы с информацией: умение определять понятия, создавать обобщения в сфере профессиональной подготовки, уста- навливать аналогии, классифицировать, самостоятельно выбирать основания и критерии для классификации явлений и процессов опережающей профессиональной подготовки, устанавливать причинно-следственные связи, строить логическое рассуждение, умозаключение (индуктивное, дедуктивное и по аналогии) и делать выводы, применять и преобразовывать знаки и символы, модели и схемы для решения задач опережающей профессиональной подготовки, смысловое чтение; умение осознанно использовать речевые средства в соответствии с задачей профессиональной коммуникации для выражения своих чувств, мыслей и потребностей в области опережающей профессиональной подготовки. Все данные требования отражены в метапредметных компетенциях, осваиваемых учащимися.

Основной задачей опережающей профессиональной подготовки является подготовка учащихся согласно динамично меняющемуся миру. В настоящее время данные изменения, в большинстве случаев, связанны с внедрением и развитием IT сферы, и в последние годы особое внимание уделяется экологическим вопросам. Учет развития компетенций в IT и развитие экологического мышления также отражены в метапредметных компетенциях предусмотренных федеральных государственных образовательных стандартах основного общего образования.

Таким образом мы видим, что несмотря на то, что требования опережающей профессиональной подготовки учащихся не отражены в ФГОС ООО в явном виде, компетенции, развиваемые при реализации опережающей профессиональной подготовки, предполагаются в нормативных документах образовательных организаций, в частности, в метапредметных результатах подготовки учащихся.

\section{ЛИТЕРАТУРА}

1. Концепция преподавания предметной области «Технология» в образовательных организациях Российской Федерации, реализующих основные общеобразовательные программы от 30 декабря 2018 года. - [Электронный ресурc]: - URL: https://docs.edu.gov.ru/document/c4d7feb359d9563f114aea8106c9a2a а (дата обращения: 08.11.2020).

2. Новиков, П.Н. Опережающее профессиональное образование: научно-практическое пособие / П.Н. Новиков, В.М. Зуев. - М.: РГАТиЗ, 2000 - 266 С.

3. Распоряжение об утверждении методических рекомендаций о реализации проекта «Билет в будущее» в рамках федерального проекта «Успех каждого ребенка» URL: https://docs.edu.gov.ru/document/9b13cece54db601d1a8c0e9cc6b7a7d7/download/2307/ (дата обращения: 22.03.2021)

4. Федеральный государственный образовательный стандарт основного общего образования (Утвержден приказом Министерства образования и науки Российской Федерации от 17 декабря 2010 г. № 1897) URL: http://standart.edu.ru/catalog.aspx?Catalogld=2588 (дата обращения: 22.03.2021)

( Кашфразыева Гульнара Камилевна (gulnara2511@bk.ru). 